
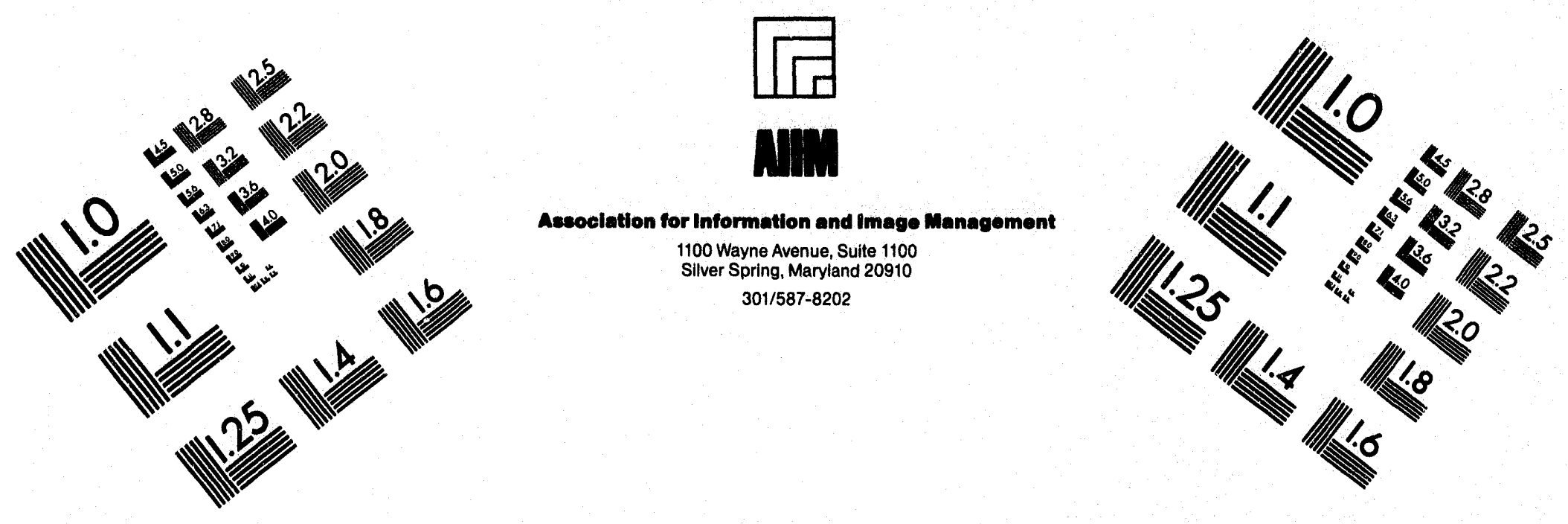

Centimeter

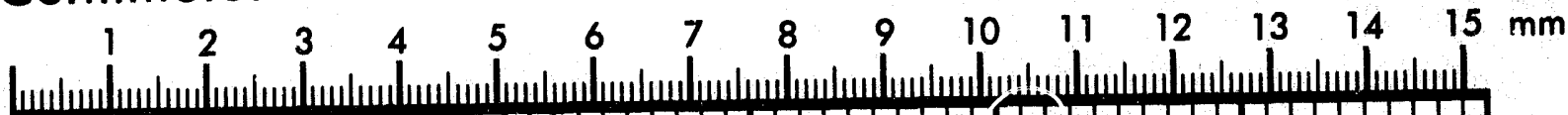

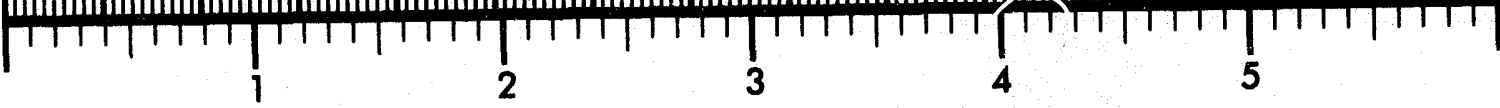
Inches
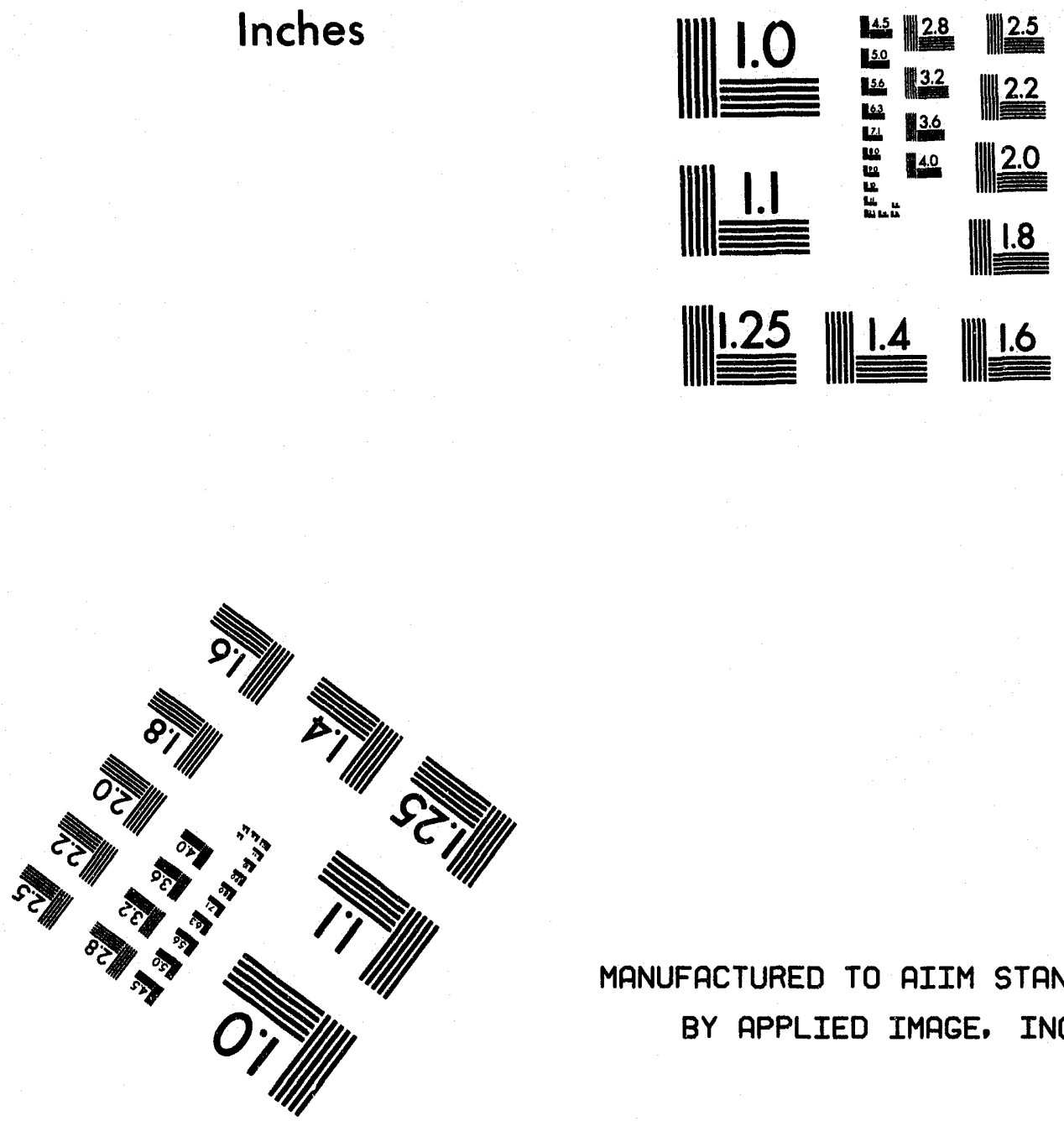

MANUFACTURED TO AIIM STANDARDS

BY APPLIED IMAGE, INC.

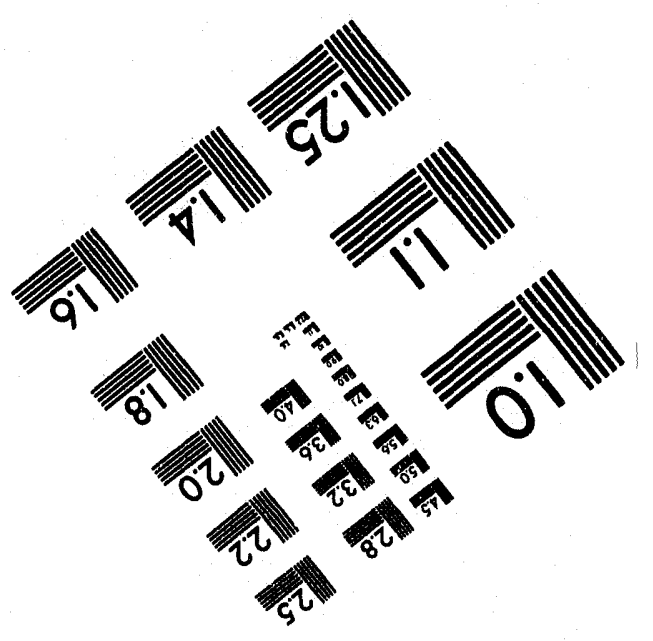



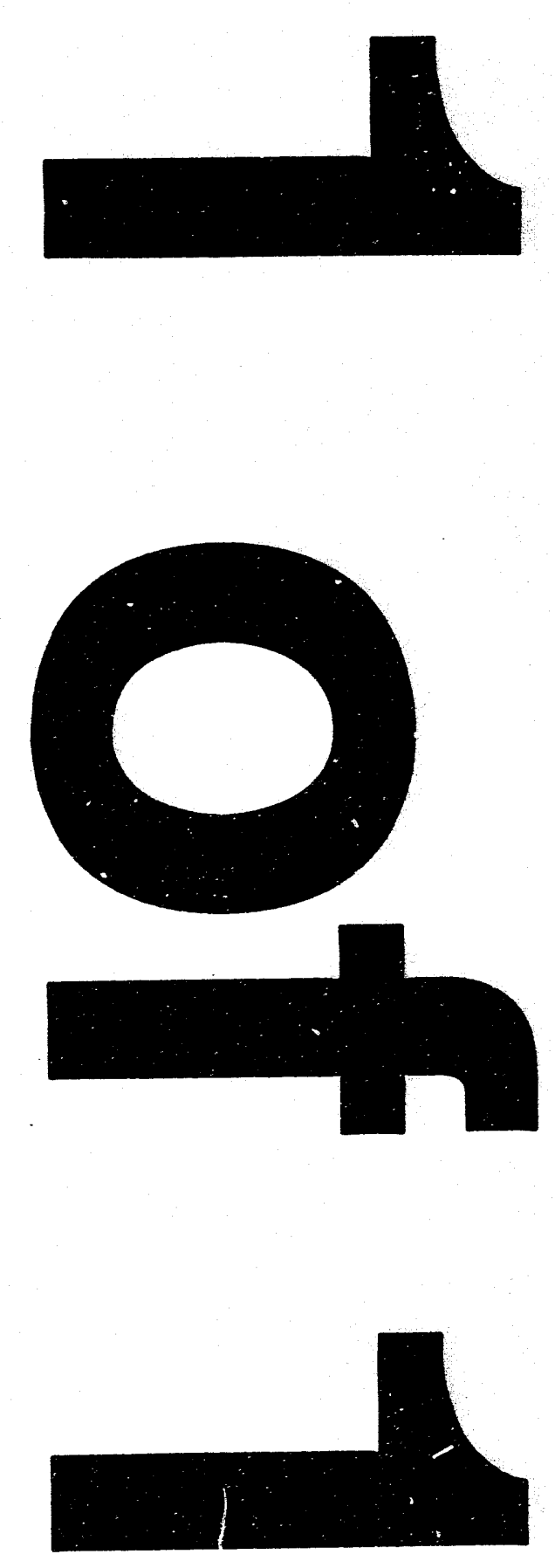


\section{TARGET AREA CHAMBER SYSTEM DESIGN FOR THE NATIONAL IGNITION FACILITY}

Richard Wavrik

Sandia National Laboratories

P.O. Box 5800 - MS 1184

Albuquerque, NM 87185

(505) 845-7644

Frank Dempsey

EG\&G, c/o SNLA

P.O. Box 5800 - M/S 1184

Albuquerque, NM 87185

(505) 845-3224

Andrew Anderson

Lawrence Livermore Laboratory

P.O. Box 808 - L-481

Livermore, CA $94551-9900$

(510) 423-9634

\author{
John Boyes \\ Sandia National Laboratories \\ P.O. Box 5800 - M/S 1184 \\ Albuquerque, NM 87185 \\ (505) 845-7090 \\ Rojelio Garcia \\ EG\&G c/o SNLA \\ P.O. Box 5800 - M/S 1184 \\ Albuquerque, NM 87185 \\ (505) $845-7751$ \\ Michael Tobin \\ Lawrence Livermore Laboratory \\ P.O. Box 808 - L-481 \\ Livermore, CA $94551-9900$ \\ (510) $423-1168$
}

\author{
Craig Olson \\ Sandia National Laboratories \\ P.O. Box 5800 - M/S 1186 \\ Albuquerque, NM 87185 \\ (505) 845-7303
Victor Karpenko
Lawrence Livermore Laboratory
P.O. Box 808 - L-490
Livermore, CA $94551-9900$
(510) $422-9256$
Jeffrey Latkowski
Lawrence Livermore Laboratory
P.O. Box 808 - L-481
Livermore, CA 94551-9900
(510) 423-9378

\section{ABSTRACT}

The National Ignition Facility (NIF) is a proposed Department of Energy facility which will contribute to the resolution of important Defense Program and inertial fusion energy issues for energy production in the future. The NIF will consist of a laser system with 192 independent beamlets transported to target chamber.

The target chamber is a multi-purpose structure that provides the interface between the target and the laser optics. The chamber must be capable of achieving moderate vacuum levels in reasonable times; it must reinain dimensionally stable within micron tolerances, provide support for the optics, diagnostics, and target positioner; it must minimize the debris from the $x$-ray and laser light environments; and it must be capable of supporting external neutron shielding. The chamber must also be fabricated from a low activation material.

The fusion reaction in the target gives off neutrons, $x$-ray and gamma rays. The $x$-rays and gamma rays interact with the interior of the target chamber wall while neutrons penetrate the wall. In order to minimize the neutron activation of components outside the target chamber and to absorb gammas emitted from the activated chamber, shielding will be placed immediately outside the chamber.

The target chamber contains the target positioner. The target positioner moves the target from outside the chamber to the center of the chamber and positions the target at the focal spot of the laser beams. The target positioner must be survivable in a harsh radioactive environment. The materials used must be low activation and have a high stiffness to weight ratio to maintain target stability.

This paper describes the conceptual design of the target chamber, target postioner, and shielding for the NIF.

\section{INTRODUCTION}

The NIF program represents a significant expansion of the existing NOVA program which has been in place at the Lawrence Livermore National Laboratory since the mid 1980's. The NOVA target chamber had piovisions for twenty laser beam ports with only ten being used. The orientation of the laser beams were from the sides of the chamber and the

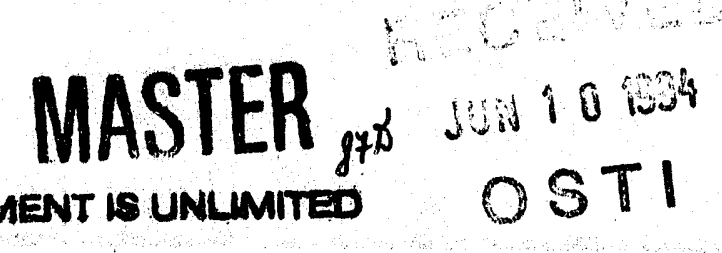


diagnostics were located in a cylindrical section which joined the two hemispherical ends. Work platforms were constructed to service the diagnostics. The 4.5 meter diameter chamber was fabricated from 5083 aluminum in a $10 \mathrm{~cm}$ thickness. This chamber design was used as a starting point for the larger 10 meter diameter NIF chamber.

As the conceptual design of the NIF target chamber progressed, the primary design criteria were defined as:

O The target chamber shall be designed based on routine deuterium-tritium (DT) fusion yield of $20 \mathrm{MJ}$, with the capability to withstand a DT fusion yield produced by a single shot of up to $45 \mathrm{MJ}$ (corresponds to $1.6 \times 10^{19}$ neutrons).

- The target chamber shall be capable of achieving a vacuum level of $5 \times 10^{-5}$ Torr in less than two hours.

O The target chamber shall be capable of accommodating diagnostic instruments necessary for fusion ignition and applications experiments.

O The resulting stresses in the target chamber shall be low enough to assure a 30 year operating life and be consistent with vacuum vessel design practices.

- The dimensional distortion of the chamber should be minimized and maintain the root-meansquare (rms) deviation in pointing of the centroids of all beams from their specified aiming points not exceeding $\mathbf{5 0}$ microns for a period of two hours before a shot.

O The target chamber shall provide mounting for shielding and confinement systems for limiting neutron activation external to the chamber. The chamber will have internal panels for mitigation of $x$ ray and debris effects and 100 and 200 unconverted light beam dumps.

- The target positioner shall be capable of placing and holding targets anywhere within $3 \mathrm{~cm}$ of target chamber center, with accuracy, repeatability, and stability consistent with the relative laser/target alignment requirements.
- The initial design of the target positioner does not have to accommodate cryogenic targets, however, its design should not preclude the upgrading to cryo targets at a later phase in the program.

\section{SYSTEM DESIGN DISCUSSION}

The target chamber will be discussed in three major sections 1) the target chamber sphere 2) shielding, and 3) the target positioning system.

\section{A. Target Chamber Sphere Design}

The orientation of the NIF chamber has been rotated $90^{\circ}$ from that of the NOVA chamber. This configuration puts the diagnostics in a horizontal location around the waist of the chamber thereby affording easier access.

The requirements for a low activation material focused on the use of 5083 aluminum alloy (as used in the NOVA chamber), or a composite material. A glass-epoxy system has the advantage of lower neutron activation than aluminum. Two methods of composite fabrication were studied. The first method was using a chopped ylass-epoxy system sprayed over a mandrel. The mandrel would be a thin wall aluminum structure with the port pipes and flanges already installed. While fabrication of this composite structure would be straightforward, there are several concerns which would need to be overcome: 1) The modulus of a chopped glass structure would be about 1/10th that of an aluminum sphere, resulting in larger static deflections; 2) if the bond between the composite and thin aluminum shell failed, atmospheric pressure would collapse the thin shell; 3) the cost of fabricating a thin aluminum shell would be similar to a thicker shell; 4 ) the thin sections would be less stable during transportation and erection. The second method of fabrication evaluated uses a resin preimpregnated cross ply glass cloth iaid over a mandrel. Several hundred layers would be used to build up to the required thickness. The final lay-up would be cured in an autoclave. The resulting structure would then be removed from the mandrel. Although the modulus of the structure, will be higher than the chopped glass structure it will still be $1 / 3$ that of an aluminum sphere. The cost of a hemispherical mandrel would also be equivalent to one-half that of a solid sphere, thus the total cost would exceed that of an aluminum chamber. The most serious difficulty with this approach is in the installation and sealing of 
ports. There is no method that will assure a vacuum tight joint. All of the epoxy composite systems will also support combustion. Because of the above issues the use of composites for the target chamber material was discarded.

A more conventional approach, using annealed 5083 aluminum would be used for the chamber. 5083 aluminum is a commercial alloy available in large plate thickness which is weldable and machineable. The 10 meter diameter of the chamber was established as a trade off between the laser optics need for short focal lengths, and the physics need to maximize the chamber size to mitigate debris formation from the wall. Any debris generated will condense on the final optic causing a maintenance problem. The thickness of the chamber is determined by the structural requirements of a vacuum vessel with port holes. The chamber must have ports for the final laser optics, diagnostics, target insertion/positioning and personnel access for maintenance. The $\mathbf{4 8}$ laser optics ports, accommodating 192 beams, located in two circular configurations defined by the inter-section of cones with approximately $27^{\circ}$ and $53^{\circ}$ polar angles. The final optics assemblies are offset from the cones by $+1-$ $4^{\circ}$. The placement of the ports are determined by the physics of the interaction with the target. Approximately 150 additional ports are needed to accommodate the diagnostic and target insertion functions. These ports are located in an area $+1-20^{\circ}$ from the chamber's horizontal waist.

The target chamber's structural stresses, buckling load factors, and deformations helped determine the required thickness. Initial calculations ${ }^{1}$ indicated that a 10 meter circular sphere, without holes, of $1.2 \mathrm{~cm}$ thickness would withstand the vacuum and buckling load. The ports increase the stresses and thus the required thickness. In addition to the presence of the port holes and vacuum loading, an additional $4500 \mathrm{~kg}$ optics load and $2300 \mathrm{~kg}$ diagnostics load is imposed at each port. The analysis of these combined loads must be done by finite element stress analysis.

The finite element analysis was done using two different codes. The EMRC NISA ${ }^{2}$ code is a personal computer based system that was used for screening the effects of thickness on stresses. The initial results indicated that a 5 to $10 \mathrm{~cm}$ thickness range would be more than acceptable for the chamber. A finer grid as well as the ability to direetly interface with the Pro- $\mathrm{E}^{3}$

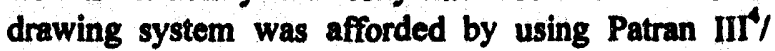

Abaqus. This system also allowed the inclusion of the final optics beam hardware that imposes a moment loading on the chamber. Both codes are in agreement in their results in stress, deflection, buckling, and natural frequencies, however, the latter code with its greater number of elements gives the more accurate values. The model included diagnostic, vacuum, shielding, and optics loads as well as a pedestal chamber support load. The initial calculations for a sphere with holes, vacuum loads, and pedestal mount indicated that $5 \mathrm{~cm}$ would be an adequate thickness. The inclusion of diagnostic, optics, and shielding loads would increase this to $10 \mathrm{~cm}$.

The maximum resulting static stress of $31.7 \mathrm{MPa}$ occurs at the pedestal/chamber interface. The ultimate stress of the 5083 aluminum is $290 \mathrm{MPa}$; thus a factor of safety of 9.1 exists. Conforming to the American Society of Mechanical Engineers (ASME) code requires a minimum factor of safety of four for an acceptable design. Buckling of the chamber was also analyzed. Although the initial analysis was performed on a spherical shell, additional cases were analyzed using distorted spheres to account for the deformations due to the static gravitational loads, as well as the manufacturing tolerance variations. Because of the $10 \mathrm{~cm}$ shell thickness, these defects had no measurable effect on the resulting stresses or the buckling load. The buckling safety factor for this design is approximately $\mathbf{5 0}$.

The chamber was also subjected to seismic loading for a Class II facility as defined in UCRL-15910 $0^{6}$. The resulting stresses and buckling load factors were found to be acceptable. The vibrational characteristics of the chamber were analyzed. There were some low frequencies associated with a rocking or torsional mode of the chamber. However, mounting spokes from the building wall will restrict these motions. The first significant vibrational mode of the chamber is a vertical resonance at $24.2 \mathrm{~Hz}$. This frequency is high enough to minimize mechanical vibration coupling from machinery. No stiffening effects from the external chamber shielding were assumed in this analysis. Inclusion of the extra thickness would stiffen the chamber resulting in higher natural frequencies. It is also recognized that the frequency of the target chamber system is highly dependent upon the mounting structure (i.e., a flexible pedestal will result in lowering the frequency of the system). The combined target chamber/support system was analyzed in a separate program within the target area 
building design. Table 1 summarizes the results of the stress analysis for the 10 meter diameter, $10 \mathrm{~cm}$ thick 5083 aluminum sphere.

\begin{tabular}{|l|r|r|}
\hline \multicolumn{3}{|c|}{ Table 1 } \\
& Stress Results \\
\hline & Static & Seismic \\
\hline Max Stress (mPa) & 31.7 & 42.7 \\
\hline Max Deflect (mm) & 2.5 & 6.1 \\
\hline $\begin{array}{l}\text { Buckling } \\
\text { (Load Factor) }\end{array}$ & 50.0 & 50.0 \\
\hline Factor of Safety & 9.1 & 6.8 \\
\hline
\end{tabular}

As was mentioned, the general size and shape of the target chamber was dictated by the physics and optics of the program. In the interest of studying the manufacturablilty of a chamber, the thickness, shape, and fabrication techniques were discussed with several potential manufacturers. The spherical shape was desirable in that it utilized standard fabrication techniques. There was no fabrication advantage to utilization of hemispherical sections joined to a cylindrical waist section. The fabrication of the sphere would be done by stamping 3-m $\times 10-\mathrm{m}$ aluminum plates into gore sections (stampings of up to $15 \mathrm{~cm}$ plate thickness are possible). These sections would be field welded into a sphere. The port holes would be cut and the faces machined or flanged pipe sections will be welded in place. No source was found that could fabricate offsite and ship such a large structure.

\section{B. Shielding and Confinement Design}

In order to achieve an average shot turnaround time of eight hours, the activation and decay dose rates of structures in the target area must be minimized. After a shot that produces sig-nificant neutron yield $\left(0.1\right.$ to $20 \mathrm{MJ}$, or $3.6 \times 10^{16}$ to $7.2 \times 10^{18}$ neutrons) the chamber will become radioactive. As was mentioned, the choice of target chamber construction material was based upon a comparison of contact dose rates on the outer surface of the chamber. While a Kelvar chamber has a virtually undetectable dose rate after less than one day, it suffers from the fabrication issues common to composite structures. A 316 stainless steel chamber has a dose rate that is 30 times greater than the $\mathbf{5 0 8 3}$ aluminum. This will prevent human access into the chamber for one to several days, depending on the yield. Since it will be necessary to have access to the target area between shots, external shielding will be applied to the target chamber which will reduce personnel exposure to less than $500 \mathrm{mrem} / \mathrm{yr}$ in the target area. Several materials were considered for shielding on the outside of the target chamber. Commercial shielding materials using lead, polycarbonates, boron mixes were considered. Also compared was a sprayable form of concrete, called "shotcrete". A decision analysis of the various materials was done considering factors such as cost, weight, support frame activation, chamber gamma shielding, shield activation, flammability, environmental concems, and decommissioning/disposal.

The shotcrete, using 5 wt. \% 5083 aluminum rebar was shown to be the most attractive choice. It is anticipated that the 5083 aluminum reinforcement bars will be welded to the chamber's exterior. Shotcrete will then be sprayed over the rebars to a final thickness of $40 \mathrm{~cm}$. The average dose rate in the vicinity of the chamber will be less than $0.64 \mathrm{mrem} / \mathrm{hr}$ 24-hours after a $100 \mathrm{~kJ}$ yield shot. The addition of lead (ten weight percent) to the concrete increases the shield density by nearly $40 \%$. The resulting increase in density and average atomic number results in improved gamma ray shielding properties. The resulting Target Area decay dose rate decreases to $0.40 \mathrm{mrem} / \mathrm{hr}$. A final decision on the shotcrete composition will be made during the detail design phase of the project.

The interior of the target chamber will be covered by replaceable panels known as "first walls". The panels will serve as either $x$-ray fluence and debris mitigators or $1 \omega$ and $2 \omega$ dump panels, depending on their placement and materials of construction.

The chamber's interior wall will be subjected to $x$ ray fluences from the target. Predictions indicated that the fluence may be sufficiently high to ablate a large amount of material from a bare aluminum chamber wall (hundreds of kilograms per year). Therefore, the walls will be protected with a coating of low-Z, high melting point material (such as boron or alumina) to minimize $x$-ray ablation. The fluence at 5 meters from the target for a $20 \mathrm{MJ}$ shot is near the predicted threshold for ablation of the boron coating and slightly above that of alumina. Although work is continuing to define the best first wall coating (alumina, zirconia, boron, and graphite) the conceptual design of NIF utilizes a $0.35 \mathrm{~mm}$ thick 
boron layer that is plasma sprayed over a nickel bond coat applied to a $0.95 \mathrm{~mm}$ thick 5083 aluminum substrate. The substrate will be panels approximately 1-meter square, replaceable, and overlapping on the chambers interior wall.

$15 \%$ of the chamber's interior wall will also be subjected to unconverted light. The $1.05-\mu \mathrm{m}$ light produced by the laser is frequency doubled and tripled at the target chamber. All three wavelengths of light $(1.05, .53$, and $.35-\mu \mathrm{m})$ enter the chamber focusing at a different location. The final optics force the $1 \omega$ and $2 \omega$ light to miss the hohlrum (target) entrance hole. This unconverted light intercepts the far wall of the chamber. While the beam ports are indexed so that unconverted light from a port on one side of the chamber does not hit an opposing beam port, some spots on the wall will reach average intensity of light up to $6 \times 10^{9} \mathrm{~W} / \mathrm{cm}^{2}$. Failure to absorb this unconverted light will result in the formation of debris from the damaged aluminum chamber's interior. Although work continues to define an acceptable, cost effective shield, initial studies indicate that panels may be comprised of a fused-silica cover on an absorbing glass substrate. These panels would be replaceable and attached to the interior of the chamber in the area of the beam ports.

\section{Target Emplacement and Positioning/Align- ment system}

The target emplacement and positioning/alignment systems are five-degree-of-freedom manipulators designed to provide a system for repeatable and stable alignment of the Target Alignment System (TAS) and the target within the target chamber. The manipulators will be inserted through opposing ports on the target chamber's horizontal waist. The target emplacement manipulator consists of two nested telescoping tubes each being approximately six meters long. The outer tube will serve as a fixed base support for structural rigidity and as a vacuum interface. It will be structurally supported outside the target chamber by two mounting saddles attached to the building floor (isolation pads will be provided to isolate the inserter from external excitation). The inner tube will be multi-sectioned varying in diameter from 30 to $20 \mathrm{~cm}$. The larger diameter will be made of aluminum to allow for mechanical fastening to the support slide system. The remaining section, which extends toward the center of the chamber will be made of a carbon/carbon composite. The inner tube will retract through a vacuum isolation valve outside the chamber. This will permit mounting of the target onto the end of the manipulator and subsequent reposition-ing inside the evacuated chamber at the beam's focal point. The manipulators will hold the target stable within $5 \mu \mathrm{m}$ over a two hour period. Positioning must be repeatable to $+1-50 \mu \mathrm{m}$.

The mechanical issues of positioning and stability are sizable, however, the target positioner will be the structure closest to the target seeing the highest neutron and $x$-ray fluences. The target positioner for cryogenic targets, which will be used for fusion yield shots, will be protected with a layer of frost (probably frozen nitrogen) on its front surface. This layer will be ablated by target emissions and will be pumped out as a noncondensible gas after the shot. Due to the neutron threat, materials producing short-lived radioactivity will be used - such as carbon/carbon composites and 5083 aluminum. Shrapnel will also cause some physical damage. Preliminary studies indicate that the last 10 to $20 \mathrm{~cm}$ of the positioner holding the target will be "lost" forming debris and shrapnel. Thus the last $20 \mathrm{~cm}$ of the positioner will be designed to have as low a mass as possible and be replaceable.

The target positioner supporting non-cryogenic targets will have its front surface steeply angled away from the target and may be coated with a layer of boron to control the direction and amount of ablated material. It is predicted that this design will lead to less than $10 \mathrm{mg}$ of material ablated per full laser energy, no yield shot. If distributed isotropically, this amount of material will deposit roughly $0.1 \mathrm{~A}$ onto the debris shield.

The TAS alignment manipulator will function in the same manner as the target manipulator. Both manipulators will occupy the center of the chamber during the alignment phase, then the target and the lasers must each be aligned to the TAS reference point. The alignment between the two is accomplished by using the optical feedback of the camera reticules, which are part of the TAS hardware system. Upon completion of alignment, the alignment manipulator will be retracted into a protective enclosure located outside the chamber wall. This manipulator should be fabricated from low activation materials but it will not be subjected to ablation as is the target positioner. 


\section{SUMMARY}

A 10 meter diameter, $10 \mathrm{~cm}$ thick aluminum target chamber has been shown in the NIF conceptual design to be a robust structure capable of supporting and providing stability to the final optics and diagnostics. The spherical vacuum vessel can be field fabricated and the ports machined maintaining a $1 / 2 \%$ accuracy of the diameter and port hole placement within 0.6 $\mathrm{cm}$. External shielding, provided by shotcrete represents a cost effective method of reducing external radiation exposure to workers in the target area. The internal panels for beam dump and $x$-ray fluence mitigation are still under study. The design concepts present in this paper will be refined during the coming year.

The conceptual designs for target emplacement and positioner/systems presented will also undergo refinement during the coming year. Designs and materials which will provide the rigidity required to maintain target position while having minimum mass and activation will be studied. The final design will be a trade off between the mechanical requirements and the formation of debris.

\section{ACKNOWLEDGMENTS}

The authors thank P. W. Stanek and R. Castro of the Los Alamos National Laboratory for the fabrication of plasma sprayed first wall test specimens.

This work was supported by the U.S. Department of Energy under Contract DE-AC04-94AL8500.

\section{REFERENCES}

1. Roark and Young, Formulas for Stress and Strain, p.549, McGraw-Hill, New York, N.Y., 5th ed., 1982.

2. Engineering Mechanics Research Corp., NISA II, Ver. 93, Troy, MI.

3. Parametric Technology Corp., Pro-Engineer, Ver. 11, Waltham, MA.

4. PDA Engineering, Patran III, Rel 1.2, Costa Mesa, CA.

This report was prepared as an account of work sponsored by an agency of the United States Government. Neither the United States Government nor any agency thereof, nor any of their employees, makes any warranty, express or implied, or assumes any legal liability or responsibility for the accuracy, completeness, or usefulness of any information, apparatus, product, or procens disclosed, or represents that its use would not infringe privately owned rights. Reference herein to any specific commercial product, process, or service by trade name, trademart, manufacturer, or otherwise does not necerearily constitute or imply its endorsement, recommendation, or favoring by the United States Government or any agency thereof. The view and opinions of authors expressed herein do not necessarily state or reflect those of the United States Government or any agency thereof.
5. Hibbitt, Karlsson \& Sorensen, Inc., ABAQUS,

6. R. P. Kennedy, et. al., Natural Phenomena Hazards Design and Evaluation Criteria for Department of Energy Facilities, UCRL-15910, Rev 2, September 1992 Draft, National Technical Information Service, Springfield, VA.

\section{DISCLAIMER}



